Article

\title{
Supplier Replacement Model in a One-Level Assembly System under Lead-Time Uncertainty
}

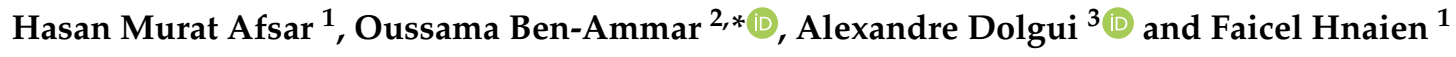 \\ 1 University of Champagne, University of Technology of Troyes, CNRS, ICD/LOSI. 12 rue Marie Curie, \\ 10010 Troyes, France; hasan_murat.afsar@utt.fr (H.M.A.); faicel.hnaien@utt.fr (F.H.) \\ 2 Department of Manufacturing Sciences and Logistics, Mines Saint-Étienne, Univ Clermont Auvergne, \\ UMR-CNRS 6158 LIMOS, CMP, 880 route de Mimet, F-13541 Gardanne, France \\ 3 IMT Atlantique, LS2N, UMR-CNRS 6004, La Chantrerie, 4 rue Alfred Kastler, 44300 Nantes, France; \\ alexandre.dolgui@imt-atlatique.fr \\ * Correspondence: oussama.ben-ammar@emse.fr
}

Received: 18 March 2020; Accepted: 9 May 2020; Published: 13 May 2020

\begin{abstract}
Supplier selection/replacement strategies, purchasing price negotiation and optimized replenishment policies play a key role in efficient supply chain management in today's dynamic market. Their importance increases even more in Industry 4.0. In this paper, we propose a joint model of replenishment planning and purchasing price negotiation in the context of supplier replacement in a one-level assembly system (OLAS) producing one type of finished product. The real component lead times are stochastic. There is consequently a non-negligible risk that the assembly process may be stopped if all components for assembly are not delivered on the due date. This incurs inventory-related costs, holding and backlogging, which should be minimized. We consider a set of suppliers characterized by their prices and the probability distributions of their lead-times, and we present a model and an approach that optimize not only replenishment policy, but also purchasing prices. For a given unit, it is possible to model several alternative suppliers with alternative pricing and lead-time uncertainties, and evaluate their impacts on the total cost: composed of holding, backlogging and purchasing costs for the assembly system. The findings of this study indicate that it can be beneficial to pay suppliers an additional purchase cost in order to reduce the holding and backlogging costs related to uncertainty. In consequence, decision makers can use the proposed approach to negotiate prices and delivery delays or to select suppliers.
\end{abstract}

Keywords: supply chain management; assembly systems; replenishment; pricing; stochastic lead times; holding cost; backlogging cost; purchase cost; optimization

\section{Introduction}

Much research has been done on efficient replenishment as a major factor in inventory control. In fact, inappropriate replenishment policies result in stock-outs or overstocks. If customer demands are unfulfilled, penalties are imposed. At the same time, overstocking drastically increases inventory costs. The optimization of replenishment often leads to the search for a trade-off between the backlogging and holding to minimize the total cost. Usually replenishment planning models are used at the operational level when the suppliers are already selected and decision makers know the lead time distributions for each of them. These distributions are obtained from statistics of past deliveries. The problem is to decide the planned lead time for each supplier and component, minimizing the total cost, which is composed of holding cost for components and backlogging cost for the finished product.

Taking into account the importance of reliability of supplier lead times, especially in assembly systems, they should be considered not only at the operational level, but also at the strategic level, at the selection of suppliers. In the latter case, the question is: how to evaluate the cost of supplier 
unreliability in an assembly system? Often the suppliers are selected uniquely on their proposal of component prices. An interesting and important question is: how to integrate the purchasing price and lead time reliability in a common model to be able to evaluate suppliers on both purchasing price and lead time reliability. Such a model would be useful not only for supplier selection but also for purchasing price negotiation as a function of reliability of lead times.

In the modern market, companies need to take every opportunity to reduce their costs and uncertainties to satisfy their customers. This makes negotiation of purchasing prices and conditions of delivery with suppliers, supplier selection and replacement if needed, key strategic considerations. Dynamic markets lead to the necessity to select suppliers dynamically by favoring those who are able to follow changes in company requirements [1]. Poor supply condition negotiation and supplier selection during a single period can have substantial negative impacts on a firm's long-term financial results [2]. Finding a suitable set of suppliers, definition of prices and effective replenishment rules are crucial issues.

In this article, a one-level assembly system (OLAS) is considered. The assembled product is composed of $n$ distinct components which are replenished from external suppliers with uncertain lead-times described by lead time probability distributions. Lead-time uncertainty is a crucial element in production systems and logistics. There are numerous factors causing lead time randomness: limited capacity of suppliers under random demand of their clients, substandard quality, worker absenteeism, machine failure, transport postponement and randomness, etc.

The motivation for this study is based on our work experience with industrial partners from two different sectors. The first one was ZF, a gearbox producer for the automotive industry. Many of ZF's suppliers are from different countries and their lead times are often subject to random deviations. This creates problems for the assembly plant in Saint Etienne (France). To reduce the negative consequences, ZF calculates the reliability of their suppliers based on past statistics. Coefficients of reliability (greater or equal to 1) were used to calculate planned lead times for each supplier by multiplying the contractual lead time by the corresponding reliability coefficient. Nevertheless, these calculations were done for each supplier separately, thus the results were not optimal. In addition, this approach was only used to parameterize their Material Requirement Planning (MRP) system, i.e., only for replenishment planning at the operational level. The aims of ZF were to find a more efficient approach which took into account the costs, and considers all suppliers together in the same model. It was also interesting to have the possibility of using such an approach to analyze their policy of supplier selection and negotiation of purchasing prices. The second example was from retail industry, Casino Group, one of biggest retailer networks in France. Once a year the Casino Group negotiates the prices with their suppliers. There are many warehouses of the group in different regions of France, some local, some regional. Many suppliers compete to deliver the same (or similar) type of product. The lead time depends on supplier and warehouse. The Casino Group searched for models to evaluate the logistic costs of different configurations. The objective was to obtain a decision aid model to decide which suppliers deliver which product, for which warehouse and with which price per product. The Casino Group agrees to increase the purchasing price if the corresponding supplier agrees to reduce the random deviations of lead times by agreeing to deliver to a specific warehouse.

The proposed model is an extension of the model in [3] but with completely new and challenging settings, specifically we are adding purchasing cost depending on the supplier reliability. This opens the possibility of finding solutions to as yet unsolved problems. In particular, whether to outsource or not. If yes, which suppliers and countries to use and also to negotiate purchase prices vs. lead time decisions, etc. The new settings led to a completely new model, involved reworking the approach, revising cost formulations, proving the properties of the model, developing new algorithms and, which is the most important, to have new managerial insights and application perspectives. The study presents a model that takes into account not only optimal assignment of component order release dates but also replacement of a critical supplier. For a given unit, the study models several alternative suppliers with alternative pricing and lead-time uncertainties, which evaluate the impact on the total assembly system. The results show that the joint pricing and replenishment optimization can increase 
system efficiency, and the approach and model can be used not only for replenishment planning and MRP parameterization but also for supplier selection and purchasing price negotiation.

Here, to be closer to real-world industrial planning methods, we consider a discrete temporal environment and integer decision variables. We consider the case of discrete lead-time distributions, as real-world industrial planning methods generally utilize the discrete temporal environment.

The rest of this paper is organized as follows. Section 2 reviews previous research on replenishment planning under random lead times with a specific focus on assembly systems. Section 3 outlines a formulation of the supplier selection/replacement and replenishment optimization model for the considered OLAS. Section 4 presents the optimization approach for the case where several suppliers may be replaced. Section 5 reports the computational results. Section 6 provides managerial insights. Theoretical contributions and limitations of our research are discussed in Section 7. Section 8 gives concluding remarks.

\section{Related Work}

The literature includes several papers that study supply planning under uncertainty: most focus on demand uncertainty, and there has been little attempt to address the question of lead-time uncertainty. Here, we do not claim to provide an exhaustive review of the literature but a broad overview of important existing approaches in the field of supply planning under lead-time uncertainty. This first analysis of the literature confirms that most existing work focuses on one-customer demand planning and one-period planning with specific structures.

Weeks [4] was one of the first authors to investigate one-demand replenishment planning for one-level production under lead-time uncertainty. He proved that the problem of planned lead-time calculation can be easily resolved by using the well-known Newsvendor model. Yano in [5] generalized the approach to the case of multi-stage linear systems, and Gong et al. in [6] proved that the problem for serial inventory systems is equivalent to the one that calculates the best base-stock levels. Elhafsi in [7] also dealt with multi-stage systems but with backlogging costs in intermediate stages. The author proposed a recursive procedure to calculate the expected total cost and then optimize planned lead times based on the convexity of the cost function.

The literature covering assembly systems under lead-time uncertainty includes several studies that consider one-customer demand planning. Yano [8] was among the first authors to study replenishment planning for one-level assembly systems (OLAS) under lead time uncertainty. In that paper, an assembly system for a finished product was considered. The finished product was assembled from two components. The lead time followed a stochastic Poisson distribution for the first component and a negative binomial distribution for the second component. Like Yano in [8], Kumar in [9] developed a model to study OLAS under a known demand and uncertain lead times, but for several types of components. The objective was to minimize the expected total cost composed of holding cost and backlogging cost. An exact method was proposed to obtain optimal order release dates. The main limitation of this method is that it is only valid for certain types of lead-time distributions (exponential, uniform or normal). Several other works have set out to demonstrate the convexity of the objective function for the case of OLAS [10] or to optimize it using Newsboy formulae with specific assumptions on lead-time probability distributions [11,12]. For the case of a single stochastic demand, [13] studied an assembly system with one finished product and two components, each purchased from its own supplier. The distributions of probabilities were of a specific type on two periods: an order is delivered at the time $t$ with probability $p$ otherwise it is delivered at the time $t+1$. The authors optimized the ordered quantity purchased from each supplier.

In [14], the authors developed a mathematical model to calculate the expected total cost, which is the sum of the inventory holding costs for components and sub-assemblies as well as the backlogging cost for the finished product, for two-level assembly systems. The components of the second level of the bill of materials (BOM) are necessary to assemble sub-assemblies. Then the sub-assemblies of the second level are used to assemble the finished product at the first level. The lead times for components and sub-assemblies are discrete random variables. The authors assumed that the finished product is 
assembled, at the earliest, on due date (Just-In-Time policy). The problem is more complex than for one-level assembly systems because of the necessity to calculate convolutions of probabilities for both level 1 and 2. A GA was proposed to minimize the expected total cost by searching for appropriate (if possible optimal) order release dates for the components at the second level. In [15-17], the authors use the same mathematical model with the same assumptions but in a multi-objective context.

Later, in the article by Ben-Ammar and Dolgui [18], the model was extended to authorize the assembly of the finished product before the due date if all the components at level 1 are available. A Branch-and-Bound procedure (B\&B) was developed to optimize the planned lead times. Based on this approach, a joint model for replenishment and equipment maintenance planning that considered system deterioration was proposed in $[19,20]$. For assembly systems with three levels in the BOM, Axsäter proposed in [21] a continuous model based on an approximate decomposition technique to optimize inventory and backlogging costs. The main limitation of these studies is that they are limited to assembly systems with less than three levels in the BOM.

The past few years have seen a huge research effort to propose more general models. To the best of our knowledge, only two studies have proposed mathematical formulations to model one-known-demand planning for multi-level assembly systems: Ben-Ammar and Dolgui in [22] for the assemble-to-order and Jansen et al. [23] for the configure-to-order environments. Even though these two studies model the dependency between levels and offer the potential to analyze replenishment planning for assembly systems with more than two levels in the nomenclature, there are still a number of unanswered questions for the case of multi-period planning where there is dependency between inventory levels at different periods.

Multi-period planning models in a stochastic environment with random lead times were investigated in many studies. Most models are limited to single-item replenishment with the assumption that there is no order crossover. The order crossover is a very well-known effect when the same type of order released at period $t$ is delivered after the order released at the period $t+1$. Despite it being a very real phenomenon in real-world replenishment planning and inventory control, in the literature, the models proposed often make the assumption that there is no crossover, because of the difficulty in calculating the probabilities of different states for a crossover effect (see [4,24-27] and their related work for well-known models, and [28-31] for real examples).

The multi-period models take into account the dependency between periods: at some point in time the backlog is covered by stocks of previous periods and vice versa [32]. For assembly systems with stochastic lead times and multi-period replenishment planning, the research was often done for the case of a known constant rather than a dynamic demand [33]. This can be explained by the fact that the order crossover is very hard to model for dynamic demand [28]. The choice of a known constant demand allows the crossover phenomenon to be neglected because the orders are of the same size, equal the demand, thus it does not matter which order is delivered on each period. A number of studies were built on this assumption to propose a one-period planning approach that is equivalent to multi-period planning with a known constant demand and stochastic lead times.

Liberatore in the work [34] was one of the first authors who proposed an economic order quantity (EOQ) approach for an OLAS under lead time uncertainty, but with only a two-period planning model. Fujiwara et al. [35] has formulated the inter-dependency between the inventories of different components in assembly systems and developed an optimal $(Q, r)$ policy for an OLAS. They assumed that: (i) the finished product is composed of several types of components; (ii) the assembly capacity is unlimited; (iii) the demand is constant and (iv) the probability distribution of procurement lead time for each component is given. Their proposed continuous model determines the optimal $(Q, r)$ policy and minimize the average total cost, which represents the sum of average inventory, backlogging and setup costs.

A few years later, new and more efficient models were developed for multi-period planning with known and constant demand. Generalized models were provided, but they were limited to OLAS. For example, in $[10,36]$, the authors have considered the MRP parameterization problem by optimizing planned lead times with a view to minimizing the expected total cost including the backlogging cost 
for finished products as well as the holding cost for components. In [37,38], the authors optimized the same expected total cost and gave the optimal safety stock and optimal safety times. However, serious weaknesses in the approach were that it is only valid if all component procurement lead times follow the same probability distribution and if all components have the same unit inventory holding cost. The optimization approach was generalized in [3] to consider procurement lead times that are independent, but not necessarily identically distributed in order to minimize the expected total cost. In continuation of this work, various approaches [36,39-42] have attempted to extend this model to study other replenishment policies (L4L, POQ, EOQ, etc.) and to include setup cost.

For the case of multi-period planning under uncertainty of both demand and lead times, Molinder [43] studied OLAS to develop a simulation model coupled with a hybrid algorithm. The algorithm is based on simulated annealing to optimize order quantities and planned lead times. In [44], the authors proposed a stochastic linear programming model to study a multi-product problem with several OLAS under both demand and lead-time uncertainty. Both these models are very interesting, but the quality of the optimal solutions depends on the number of scenarios that increases very quickly.

As can be seen in Table 1, all the papers concentrate on ordering policies by optimizing order quantities, order release dates and planned lead times [33]. To the best of our knowledge, in the field of OLAS with multi-period planning no papers have attempted to co-optimize purchasing policies and pricing strategies even though both are crucial to successful supply chain management. Most of the literature on supplier diversification and responsive pricing has focused on the single-item purchasing case. Interested readers can refer to the-state-of-the-art surveys of [45-48] to obtain more details on existing pricing models, and to the recent review paper [49] which provides an excellent overview of contributions to this issue.

In the field of inventory control for assembly systems in an uncertain environment, the issue of supplier diversification and supplier selection/replacement strategies has not been sufficiently studied. As aforementioned, Gurnani et al. in [13] studied an assembly system with one product stochastic demand. The finished product was assembled from two components. The authors extended the model introduced in [50] to consider delivery of the required components by a joint supplier or by two different suppliers. They demonstrated the optimality of base-stock when one supplier is selected. A few years later, the same authors [51] replaced lead-time uncertainty by yield uncertainty and came up with propositions under which it can be economically beneficial for the company to multi-source rather than use a single supplier. Pan and So in [52] considered an ATO environment to study random yields and price-dependent demand in single-period planning. They modeled the assembly of a finished product from $n$ components and analyzed the effects of uncertainty on the optimal solution, defined by the production quantities-product pricing dyad.

In this paper, we extend the model proposed in [3] in order to investigate an OLAS under lead-time uncertainty and to examine the benefit of paying suppliers an additional purchase cost (APC) in order to reduce the costs of component lead-time uncertainty. In [3], a one-level assembly system was considered with several suppliers and random supplier lead times. The authors optimized planned lead-times for a fixed set of selected suppliers, taking into account the statistics on the real lead times. There was no possibility of changing suppliers nor of modifying the planned lead time distributions. The objective function was to minimize the total holding and backlogging cost. That model was a model of production planning under lead time uncertainties. Such models are often used for MRP parameterization. In this paper, the motivation is different. We will try to show that the selection of suppliers does not depend only on purchasing prices, but also on the supplier lead times (reliability). The goal is to develop a model allowing supplier selection and price negotiation. The question is: what is the cost saving related to better reliability (reduction of the scope of the distributions of probabilities of lead times) taking into account holding and backlogging costs (as in the model [3]), but also purchasing costs which can be modified depending on the lead time distributions offered. To reach our objective, we will examine the benefit of paying suppliers an APC in order to reduce the lead time uncertainty. 
Table 1. Literature on assembly systems under uncertainty of lead times.

\begin{tabular}{|c|c|c|c|c|c|}
\hline \multirow{2}{*}{ Authors } & \multicolumn{4}{|c|}{ System Characteristics } & \multirow{2}{*}{ Comments } \\
\hline & $\begin{array}{l}\text { Number } \\
\text { of Levels }\end{array}$ & $\begin{array}{l}\text { Number of } \\
\text { Components }\end{array}$ & $\begin{array}{l}\text { Number } \\
\text { of Periods }\end{array}$ & $\begin{array}{c}\text { Purchasing } \\
\text { Policy }\end{array}$ & \\
\hline [4] & 1 & 1 & 1 & \multirow{14}{*}{$\sqrt{ }$} & Newsvendor model. \\
\hline [8] & 1 & 2 & 1 & & Non linear programming, safety stock. \\
\hline [9] & 1 & $n$ & 1 & & Valid for certain types of lead-time distributions (exponential, uniform or normal). \\
\hline [10] & 1 & $n$ & 1 & & Continuous distribution, iterative algorithm. \\
\hline [13] & 1 & 2 & 1 & & Specific assumptions on lead-time probability distributions. \\
\hline [14-18] & 2 & $n$ & 1 & & Mathematical models, GA, B\&B. \\
\hline$[19,20]$ & 2 & $n$ & 1 & & Replenishment and equipment maintenance planning. \\
\hline [21] & 3 & $n$ & 1 & & Continuous model, approximate decomposition technique. \\
\hline [22] & $m$ & $n$ & 1 & & ATO environment, mathematical model, B\&B. \\
\hline [23] & $m^{*}$ & $n$ & 1 & & CTO environments, mathematical model, assembly process fed by a multi-stage parallel process. \\
\hline [34] & 1 & $n$ & 2 & & Constant demand, EOQ policy. \\
\hline [35] & 1 & $n$ & $p$ & & Constant demand, $(Q, r)$ policy. \\
\hline$[37,38]$ & 1 & $n$ & $p$ & & Constant demand, the same probability distribution and the same inventory cost for all components. \\
\hline$[3,36,39-42]$ & 1 & $n$ & $p$ & & Constant demand, several probability distribution, L4L, POQ and EOQ policies. \\
\hline Current paper & 1 & $n$ & $p$ & $\sqrt{ }$ & Constant demand, supplier replacement model, HGA. \\
\hline
\end{tabular}

$m^{*}$ : assembly process fed by a multi-stage parallel process, $m$ : multi-level, $n$ : multi-components, $p$ : multi-period. 


\section{Problem Description}

The problem of replenishment in assembly systems under component lead time uncertainties is complex. This is due to the fact that it is necessary to have all the components to start the assembly process. If delivery of a component is delayed, the entire process is stopped and it is necessary to pay additional holding costs for the components which are already in stock, and backlogging costs for the finished product. Thus, the randomness of component delivery times should be reduced and, if this is impossible, it should be taken into account in production planning at all decision levels. A supplier is considered as more reliable if there is less randomness in its lead times.

In this paper, an assembly system is considered to assemble a given product. The demand in finished product is known and fixed, i.e., we know how many finished products it is necessary to assemble by the end of each period (fixed demand). To assemble one product, $n$ different components are necessary. The components are ordered from external independent suppliers. The lead times (the time between order release and component delivery to assembly system) of suppliers are independent random discrete variables with known distributions of probabilities. There is no assumption about the form of distributions of probabilities. Any discrete distributions can be used, but these distributions are known before optimization. They are obtained from statistics on the past deliveries of similar components from the same suppliers. The assembly capacity is considered as infinite. We know the unit holding cost per component and per period and the unit backlogging cost per period for the finished product. The orders for components are given at the beginning of each period. The ordered components are delivered at the end of a period. We also know the unit purchasing cost of each component from the selected supplier. The purchasing cost can be increased if the supplier agrees to reduce the randomness of its lead time. The objective is to find the planned lead time and unit purchasing cost, minimizing the total cost.

This is a problem of both replenishment and pricing in assembly systems with stochastic component lead times. It appears at the contracting stage when the planned lead times and prices are negotiated with suppliers. The model developed can also be used for supplier selection and replacement.

In our previous work, we have already studied the replenishment part of the problem. The developed approach was based on modeling the possible states of the system (orders in progress) with Markov chains, analysis of the convergence and steady state probabilities and finally obtaining steady state expressions of expected cost composed of expected holding cost for components and backlogging cost for finished products [37]. The obtained cost functions were nonlinear with discrete decision variables (planned lead times). To optimize them, a B\&B and genetic algorithms were developed and tested [3]. In addition, their efficiency is demonstrated.

In this paper, we will use our previous results and extend the models to the case of optimization of both replenishment and pricing. First of all, we will present this extended problem, the cost function for the steady state (mathematical expectation of the cost composed of holding cost for components, purchasing cost for components and backlogging cost for finished products), an optimization approach to determine the best decision variables (prices and planned lead times) and finally numerical tests and managerial insights.

In an OLAS with $n$ different components replenished from $n$ independent suppliers, the uncertainty of component replenishment lead times causes a high component inventory level and a backlog for the finished product. In this context, the producer may be ready to pay an additional purchasing cost (APC) if the supplier can decrease the uncertainty of their lead times. In this paper, we consider a purchasing and replenishment optimization model for such systems. It was developed to measure the effects of such a policy and to optimize the total cost composed of purchasing, holding and backlogging costs. Our model is based on existing models for replenishment planning under lead-time uncertainties. It assumes that assembly system capacity is infinite and that demand for the finished product is known. For each component, the lead time may take several values with given corresponding probabilities. Models of this type have already been formulated in $[36,40]$ for one-level multi-period problems and in $[15,22]$ for multi-level one-period assembly systems with random lead times. 
We will introduce additional decision variables and cost dealing with purchasing policies. Instead of optimizing only planned lead times, we will also optimize the choice of purchasing policy. Every purchasing policy $j$ for a given supplier $i$ has a purchasing $\operatorname{cost}\left(P C_{i}^{j}\right)$.

This paper uses the following notations (see Table 2):

Table 2. Notation.

\begin{tabular}{|c|c|}
\hline Parameters & \\
\hline $\begin{array}{l}i \\
j \\
h_{i} \\
b \\
H=b+\sum_{i=1}^{n} h_{i} \\
L_{i}^{j} \\
u_{i}^{j}\end{array}$ & $\begin{array}{l}\text { supplier index, } \\
\text { purchase price index, } \\
\text { unit stock cost of the product purchased from supplier } i \text {, } \\
\text { unit backlog cost for one finished product, } \\
\text { global holding and backlog cost for one finished product, } \\
\text { random lead time for supplier } i \text { under purchasing price } j \text {, } \\
\text { maximum lead time } i \text { under purchase price } j \text {; i.e., } 1 \leq L_{i}^{j} \leq u_{i}^{j} \text {. }\end{array}$ \\
\hline \multicolumn{2}{|l|}{ Variables } \\
\hline$x_{i}^{j}$ & $\begin{array}{l}\text { planned lead time for supplier } i \text { with purchase price } j \text {, } \\
\text { (planned lead time is equal to order release date if due date is equal to zero), }\end{array}$ \\
\hline \multicolumn{2}{|l|}{ Functions } \\
\hline $\begin{array}{l}P C_{i}^{j} \\
E\left(L_{i}^{j}\right) \\
F_{i}^{j}\left(x_{i}^{j}\right) \\
p_{i}^{j}(k)\end{array}$ & $\begin{array}{l}\text { purchase cost under the purchase price } j \text { for supplier } i \text {, } \\
\text { expected lead-time value for supplier } i \text { under purchase price } j \text {, } \\
\text { cumulative distribution function of lead time for supplier } i \text { under purchase price } j \text {, } \\
\text { probability of having a lead time equal to } k \text { for supplier } i \text { under purchase price } j \text {. }\end{array}$ \\
\hline
\end{tabular}

As the basic model, i.e., without taking into account PC, we will use the model proposed in [3] which consists of minimizing the expected cost composed of the sum of the component holding cost and backlogging cost of the finished product:

$$
\min E C(X)=\sum_{i=1}^{n} h_{i}\left(x_{i}-E\left(L_{i}\right)\right)+H \sum_{k \geq 0}\left(1-\prod_{i=1}^{n} F_{i}\left(x_{i}+k\right)\right)
$$

s.t.

$$
\begin{array}{ll}
1 \leq x_{i} \leq u_{i} & \forall i=1, \ldots, n \\
x_{i} \in \mathbb{N} & \forall i=1, \ldots, n
\end{array}
$$

where:

$$
X=\left(x_{1}, x_{2}, \ldots, x_{i}, \ldots, x_{n}\right)
$$

Remark 1. In this paper, we extend the model developed in [3] and treat the problem differently. Nevertheless, the techniques calculating component holding $(H C(X, Y))$ and backlogging $(B C(X, Y))$ costs are unchanged. These cost functions are explained in detail with mathematical proofs in $[3,53]$.

To solve this non-linear optimization problem in Equations (1)-(3), a B\&B was developed in [3].

We will extend this model by including the APC explained above. In other words, we integrate prices (purchase costs) as additional decision variables into this model. Our model with the new objective function in Equation (4) is expressed as follows: 


$$
\begin{array}{r}
\min E C(X, Y)=\sum_{i=1}^{n} \sum_{j=0}^{u_{i}^{0}-1} P C_{i}^{j} \cdot y_{i}^{j}+\sum_{i=1}^{n} \sum_{j=0}^{u_{i}^{0}-1} y_{i}^{j} \cdot h_{i}\left(x_{i}^{j}-E\left(L_{i}^{j}\right)\right) \\
+H \cdot \sum_{k \geq 0}\left(1-\prod_{i=1}^{n}\left(\sum_{j=0}^{u_{i}^{0}-1} y_{i}^{j} \cdot F_{i}^{j}\left(x_{i}^{j}+k\right)\right)\right)
\end{array}
$$

s.t.

$$
\begin{array}{rc} 
& \sum_{j=0}^{u_{i}^{0}-1} y_{i}^{j}=1 \quad \forall i=1, \ldots, n \\
x_{i}^{j} \leq\left(u_{i}^{0}-j\right) \cdot y_{i}^{j} & \forall i=1, \ldots, n, \forall j=0, \ldots, u_{i}^{0}-1 \\
x_{i}^{j} \in \mathbb{N} & \forall i=1, \ldots, n \quad \forall j=0, \ldots, u_{i}^{0}-1 \\
y_{i}^{j} \in\{0,1\} \quad \forall i=1, \ldots, n \quad \forall j=0, \ldots, u_{i}^{0}-1
\end{array}
$$

The objective function in Equation (4) represents the mathematical expectation of the total cost composed of purchase cost (noted $P C(Y)$ ), backlogging cost (noted $E B C(X, Y)$ ) and holding component costs (noted $E H C(X, Y))$ :

$$
\begin{array}{r}
P C(Y)=\sum_{i=1}^{n} \sum_{j=0}^{u_{i}^{0}-1} P C_{i}^{j} \cdot y_{i}^{j} \\
E B C(X, Y)=b \cdot \sum_{k \geq 0}\left(1-\prod_{i=1}^{n}\left(\sum_{j=0}^{u_{i}^{0}-1} y_{i}^{j} \cdot F_{i}^{j}\left(x_{i}^{j}+k\right)\right)\right) \\
E H C(X, Y)=\sum_{i=1}^{n} \sum_{j=0}^{u_{i}^{0}-1}\left(y_{i}^{j} \cdot h_{i}\left(x_{i}^{j}-E\left(L_{i}^{j}\right)\right)\right)+\sum_{i=1}^{n}\left(h_{i}\right) \cdot \sum_{k \geq 0}\left(1-\prod_{i=1}^{n}\left(\sum_{j=0}^{u_{i}^{0}-1} y_{i}^{j} \cdot F_{i}^{j}\left(x_{i}^{j}+k\right)\right)\right)
\end{array}
$$

Without taking into account the APC, the backlogging cost is equal to $b \cdot \max _{i=1, \ldots, n}\left(L_{i}-x_{i}\right)$. We know that $L_{i}$ is a positive random discrete variable with a finite number of possible values and $F_{i}($. is its cumulative distribution function. Thus, the expected value of the backlogging cost is equal to $b \cdot \sum_{k \geq 0}\left(1-\prod_{i=1}^{n} F_{i}\left(x_{i}+k\right)\right)$ where $F_{i}\left(x_{i}+k\right)=P\left(L_{i} \leq x_{i}+k\right)$. If we integrate purchase prices as additional decision variables, we can easily deduce $E B C(X, Y)$ expressed in Equation (10). In the same way, we can calculate $E H C(X, Y)$ expressed in Equation (11).

Constraints in Equation (5) express the fact that only one purchasing policy $\left(j=0, \ldots, u_{i}^{0}-1\right)$ is selected for each supplier $(i=1, \ldots, n)$. Constraints in Equation (6) ensure that each planned lead time $x_{i}^{j}$ is limited by an upper bound. This upper bound for the purchasing policy $(j=0)$ is equal to $u_{i}^{0}$.

The goal is to minimize Equation (4) subject to Equations (5)-(8). This minimization is fairly difficult because the objective function is not linear and because decision variables $X=\left(x_{i}^{j} ; i=\right.$ $\left.1, \ldots, n ; j=0, \ldots, u_{i}^{0}-1\right)$ are integer and $Y=\left(y_{i}^{j} ; i=1, \ldots, n ; j=0, \ldots, u_{i}^{0}-1\right)$ are binary. We note that the B\&B algorithm proposed in [3], cannot be used for this new problem, because the bounds and properties are no longer valid. Moreover, the problem is more complex, thus we will develop an optimization approach for it based on a genetic algorithm (GA) and two bounds to verify the usefulness of our approach.

\section{Optimization Approach}

In order to verify the pertinence of the replacement of critical suppliers and thus validate our approach, a GA, and lower and upper bounds are developed. These bounds will also allow us to assess the efficiency of GA. The first bound is a lower bound of our model. The objective is to verify 
that our GA gives solutions very close to this bound. The second bound which is an upper bound will allow us to judge the usefulness of our approach. This will enable us to answer the following question: does a solution based on our approach really dominate the best solution without APC?

\subsection{Genetic Algorithm}

For the general case where the costs and distributions are different, problem complexity makes it impossible to find an exact method. Thus, we will develop a genetic algorithm somewhat inspired from the one in [14] but with a new cost function (new fitness) integrating different purchasing policies and other improvements. We will exploit the results obtained for a particular case in [54] to propose a heuristic algorithm for initial population generation and to reduce the search space.

Genetic algorithms are inspired by a process of natural selection [55,56]. A group of individuals (population of solutions) go through a reproduction phase during which the good solutions pass their genetic material to generations further down. Genetic diversity by operations such as mutations avoids a premature convergence to a local optimum (see Algorithm 1).

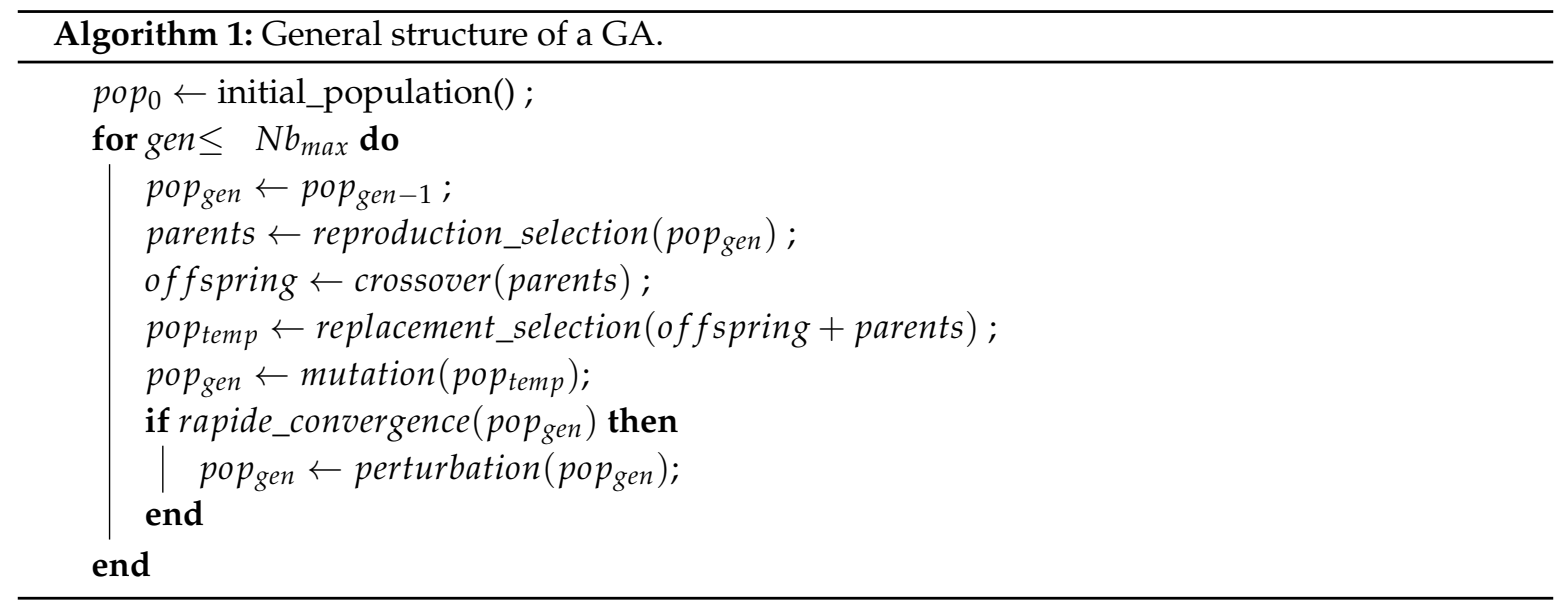

The following sub-sections present key elements of the genetic algorithm such as crossover and mutation operators along with the representation of the solution (or chromosome).

\subsubsection{Chromosome Representation of a Solution}

The chromosome representation must contain all the information necessary for a solution. If the representation fails to encode a possible solution, the genetic algorithm will naturally fail to find it.

In our algorithm, a chromosome has two chromatids that correspond to the two types of decision variables: purchasing policy (or price) $j$ from supplier $i$, and order release date $\left(x_{i}^{j}\right)$ (see Figure 1 ). The purchase release date depends on the purchasing policy.

Chromosome length: $2 \times \mathrm{n}$

\begin{tabular}{l|l|l|l|l|l|l|l|l|l|}
\hline 0 & 2 & 1 & 3 & 2 & 5 & 1 & 3 & 1 & 2 \\
\hline
\end{tabular}
Purchase policies
Purchase order dates

Figure 1. Chromosome representation.

\subsubsection{Initial Population}

An initial population of size $_{\text {pop }}$ should have an equilibrium between randomly-generated solutions designed to increase diversity and potentially good solutions needed to lead the algorithm 
towards better results. For that reason, our approach features two types of individuals in the initial population: $90 \%$ of the individuals are generated randomly, while the rest are obtained using a heuristic approach (see Algorithm 2):

- Randomly-generated solutions: a purchasing policy is chosen for each supplier following a uniform distribution. Once a purchasing policy is determined, order date is generated randomly according to the purchasing policy (order date should be less than or equal to $u_{i}^{j}$ ).

- Heuristic solutions take one of the suppliers (i) as the seed and all the others as clones of the seed to obtain an instance of the particular case explained in [54], $\left(M I P_{i}\right)$. The corresponding linear model is solved with a commercial solver (CPLEX 12.6) to obtain sol $l_{i}$ which is added into the solution pool sol_pool.

- Finally, the solution pool is sorted according to the total cost and first size $e_{p o p} \times 10 \%$ is included in the initial population.

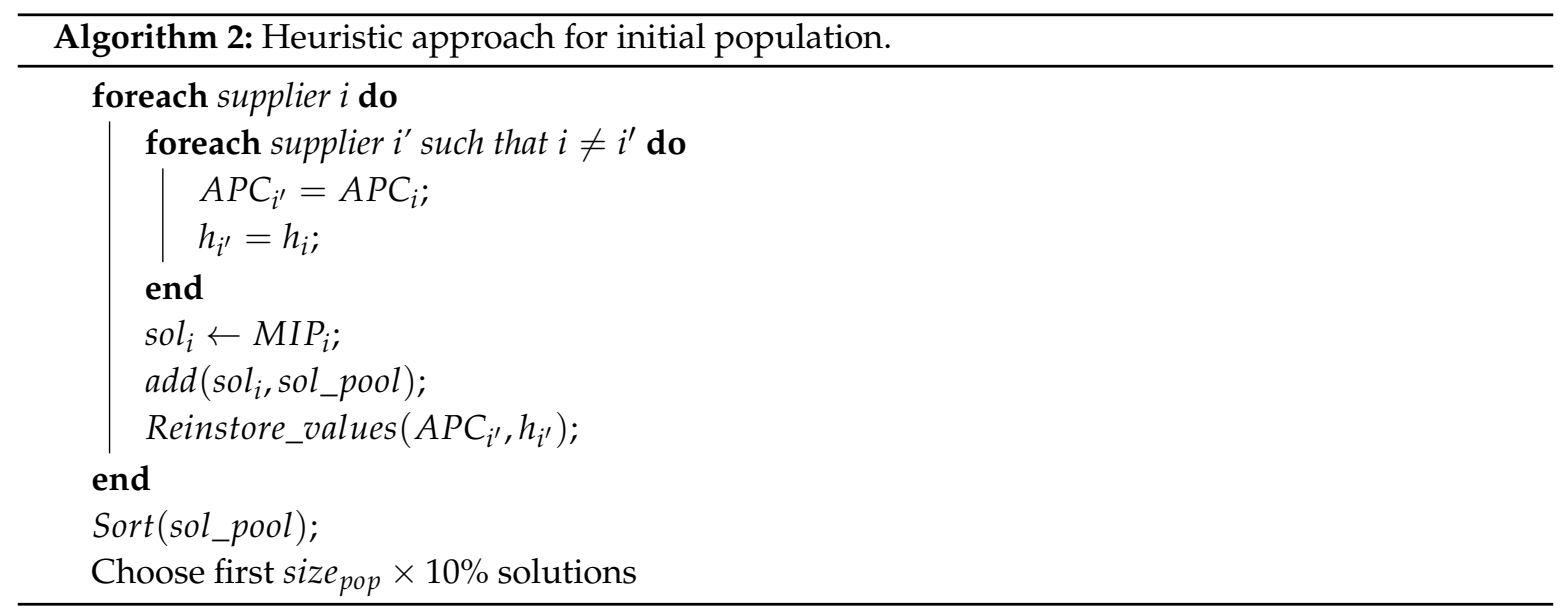

After the crossover, the offspring is added to the population, and so the population size increases by size $e_{p o p} \times p_{c o}$ on average, because for each couple, two offspring are generated with a probability $p_{c o}$. The best size pop solutions from this larger population are then kept. With this procedure, the offspring are not only in competition with their parents but also with other parents and offspring. The new set of size $_{\text {pop }}$ individuals is then subject to a mutation phase, before becoming the next generation.

\subsubsection{Reproduction selection}

Our GA uses a random selection method in which the probability of selection is uniformly distributed for each individual. This method determines $\frac{\text { size }_{\text {pop }}}{2}$ couples where each individual can only appear in one couple. With a probability $p_{c o}$, every couple undergoes crossover.

\subsubsection{Crossover operator}

A special crossover operator is applied to each couple: two chromatids of the chromosome are cut at the same position. The purchasing policy and order date information for the same supplier(s) is transmitted to the offspring. Figure 2 gives an example of a single-point crossover on two chromatids.

\subsubsection{Mutation Operators}

To introduce the right amount of diversity to the population, each individual undergoes mutation with a probability of $p_{m}$. We consider three types of mutations: randomly changing a supplier's purchasing policy $\left(m_{1}\right)$, randomly changing a supplier's order release date $\left(m_{2}\right)$ and permuting the purchasing policies and order release dates of two different suppliers $\left(m_{3}\right)$.

For the mutation operators $m_{1}$ and $m_{2}$, we need to verify that the purchasing policy and order release date are suitable. After $m_{1}$ (respectively, $m_{2}$ ), if the order date (respectively, purchasing policy) 
is unsuitable, then another date is randomly attributed to the supplier concerned. This verification is not necessary for the third mutation operator, because the genes concerning purchase policies and order release dates are swapped at the same time.

Each mutation can occur with the following probabilities:

$$
p_{m_{1}}=p_{m_{2}}=\frac{p_{m_{3}}}{2}=\frac{p_{m}}{4}
$$

If during nbIterMax ${ }_{\text {NoImprovement }}$ iterations the best solution known so far is not improved, then the probability of mutation $\left(p_{m}\right)$ is updated to $50 \%$. As soon as the best solution is improved, $p_{m}$ retakes the original value.
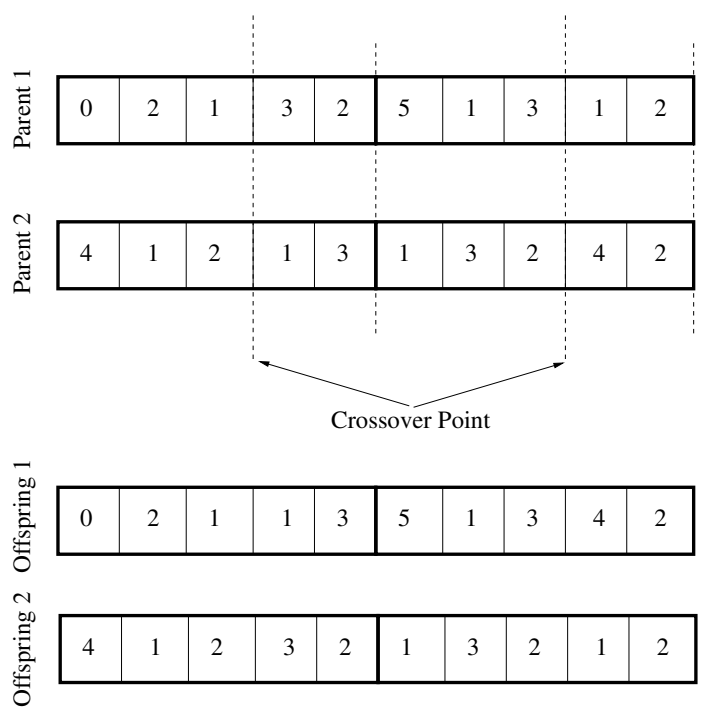

Figure 2. Single-point crossover on two chromatids.

\subsubsection{Perturbation}

If the current mutation operators are not enough to prevent a premature convergence, then a perturbation procedure is applied. Premature convergence is declared if $80 \%$ of a population has the same cost. The perturbation consists of destroying $90 \%$ of the solutions that have the same cost and replacing them with completely random but feasible solutions.

\subsection{Lower and Upper Bounds}

\subsubsection{Lower Bound}

To improve the performance of the GA, we can develop a lower bound on $E C(Z)$ from this model by decomposing it into $n$ sub-problems. In other words, instead of one final product with $n$ components, we will consider $n$ final products, each having only one component. Therefore, for each supplier $i$, we will solve:

$$
\begin{aligned}
& \min E C_{i}\left(Z_{i}\right)=\sum_{j=0}^{u^{0}-1} \sum_{s=1}^{u_{0}} z_{j}^{s} \cdot A P C^{j}+\sum_{j=0}^{u^{0}-1} \sum_{s=1}^{u_{0}} z_{j}^{s} \cdot s \cdot h \\
& -\sum_{j=0}^{u_{0}-1} \sum_{s=1}^{u_{0}} h \cdot z_{j}^{s} \cdot E\left(L^{j}\right)+H \sum_{k \geq 0}\left(1-\left(\sum_{j=0}^{u_{0}-1} \sum_{s=1}^{u_{0}} z_{j}^{s}\left(F^{j}(s+k)\right)\right)\right)
\end{aligned}
$$

s.t.

$$
\sum_{s=1}^{u_{0}} \sum_{j=0}^{u_{0}-1} z_{j}^{s}=1
$$


The total cost $(E C(Z))$ of the problem in Equations (4)-(8) is greater than the sum of $E C_{i}\left(Z_{i}^{*}\right)$. Obviously, this solution is unfeasible, because the assembly process needs to synchronize the component flows, which then causes an additional cost. Therefore, this sum is a lower bound for $E C(Z)$.

\subsubsection{Upper bound}

We can compute the upper bound using two methods presented in [39]. However, [39] has no decision concerning purchasing policy (there is only one purchasing policy, i.e., a fixed price) and the authors only find the release (purchasing) dates that minimize some of the holding and backlogging costs under lead-time uncertainty. Ref. [39] proposed an exact method (B\&B) and a heuristic (beam search), which can be used to find upper bounds for the problem considered in this paper.

\section{Experimental results}

The GA was coded in C++ and numerical experiments were performed on an Intel Core i5-2520M processor at $2.50 \mathrm{GHz}$ clock-speed and with 4GB of memory. The linear model in Equations (13)-(14) is solved by a commercial solver (CPLEX 12.6).

The solution approach was tested on a randomly-generated instance set $(I)$. We created 10 instance families as a function of component numbers $[10,20, \ldots, 100]$, and 100 test instances were generated for each family. The input data for each instance was: unit component holding cost; unit finished product backlogging cost; additional purchasing cost per component per purchasing policy; and cumulative distribution function of lead times per component per purchasing policy.

After some preliminary tests, parameter values were assigned as follows: population size ( size $\left._{\text {pop }}\right)$ to 100 , maximum number of generations $\left(N b_{\max }\right)$ to 1000 , maximum number of iterations without improvement (nbIterMax NoImprovement) to 50, probability of crossover $\left(p_{c o}\right)$ to $90 \%$ and probability of mutation $\left(p_{m}\right)$ to $10 \%$. The convergence and performance of the proposed algorithms were studied. The results were also compared with the bounds presented in the previous section.

In Tables 3-6, the first column gives the number of components (suppliers) for each instance family, the second column gives the average number of iterations where the best solution was found and the third column gives the average gap between the best solution $\left(\right.$ best $\left._{s o l_{0}}\right)$ in the initial population and

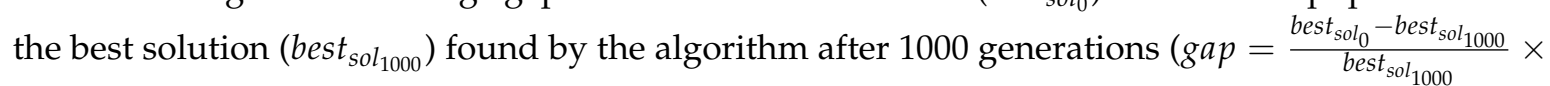
100). The next column provides the average gap between the best solution ( best $\left._{\text {sol }}{ }_{1000}\right)$ found by the algorithm after 1000 generations and the best solution ( best $_{s o l *}$ ) among all versions of GA (gap* = $\frac{\text { best }_{\text {sol }_{1000}}-\text { best }_{\text {sol } *}}{\text { best }_{\text {sol } *}} \times 100$ ), i.e., the best known solution (BKS). Finally, the last column reports the average time to execute the algorithm.

Table 3 reports the results of the genetic algorithm denoted as GA, i.e., without the complementary procedures described above (a heuristic to form the initial population and the perturbation procedure). It shows that even if there is a considerable improvement in the initial population, the gap between the solutions obtained and the BKS is still very large. The average gap on all the instances is $87.06 \%$. Table 4 presents the results of the genetic algorithm noted $G A_{P}$, i.e., with the perturbation procedure. There is only a very slight improvement, as the total average gap is no less than $86.14 \%$. Table 5 demonstrates excellent performances of the genetic algorithm noted $G A_{H}$. This algorithm includes the heuristic to design an initial population. It dramatically improves the quality of the solutions, as the total average gap to the BKS on all instances is reduced to only $3.92 \%$.

Finally, almost all the BKS were obtained with $G A_{H+P}$ (Table 6), which achieves a total average gap of $0.67 \%$. Tables $3-6$ also show that even on the largest instances, the mean execution time of the $G A_{H+P}$ is less than 1.6 seconds. 
Table 3. Results obtained by genetic algorithm (GA).

\begin{tabular}{ccccc}
\hline $\begin{array}{c}\text { Instance } \\
\text { Family }\end{array}$ & $\begin{array}{c}\text { Average Number } \\
\text { of Iterations }\end{array}$ & $\begin{array}{c}\text { Mean Gap } \\
\mathbf{( \% )}\end{array}$ & $\begin{array}{c}\text { Mean Gap * } \\
\text { from BKS (\%) }\end{array}$ & $\begin{array}{c}\text { CPU Time } \\
\text { (s) }\end{array}$ \\
\hline 10 & 38.23 & 147.26 & 19.04 & 0.28 \\
20 & 128.26 & 159.75 & 44.50 & 0.38 \\
30 & 275.96 & 178.03 & 44.87 & 0.48 \\
40 & 251.50 & 151.65 & 85.33 & 0.55 \\
50 & 368.22 & 131.95 & 102.88 & 0.63 \\
60 & 472.86 & 135.45 & 108.37 & 0.74 \\
70 & 570.92 & 148.98 & 108.97 & 0.86 \\
80 & 647.76 & 158.66 & 105.80 & 0.97 \\
90 & 697.04 & 161.99 & 105.00 & 1.08 \\
100 & 844.43 & 135.71 & 145.85 & 1.41 \\
\hline
\end{tabular}

Table 4. Results obtained by $G A_{P}$.

\begin{tabular}{ccccc}
\hline $\begin{array}{c}\text { Instance } \\
\text { Family }\end{array}$ & $\begin{array}{c}\text { Average Number } \\
\text { of Iterations }\end{array}$ & $\begin{array}{c}\text { Mean Gap } \\
\mathbf{( \% )}\end{array}$ & $\begin{array}{c}\text { Mean Gap * } \\
\text { from BKS (\%) }\end{array}$ & $\begin{array}{c}\text { CPU Time } \\
\text { (s) }\end{array}$ \\
\hline 10 & 148.06 & 162.23 & 11.09 & 0.31 \\
20 & 172.08 & 160.86 & 44.01 & 0.46 \\
30 & 306.38 & 178.86 & 44.44 & 0.59 \\
40 & 251.00 & 151.65 & 85.33 & 0.65 \\
50 & 385.06 & 132.32 & 102.62 & 0.73 \\
60 & 533.07 & 135.62 & 108.24 & 0.88 \\
70 & 593.01 & 148.96 & 108.99 & 0.99 \\
80 & 698.12 & 158.73 & 105.74 & 1.11 \\
90 & 728.58 & 161.89 & 105.09 & 1.27 \\
100 & 837.98 & 135.69 & 145.88 & 1.59 \\
\hline
\end{tabular}

Table 5. Results obtained by $G A_{H}$.

\begin{tabular}{ccccc}
\hline $\begin{array}{c}\text { Instance } \\
\text { Family }\end{array}$ & $\begin{array}{c}\text { Average Number } \\
\text { of Iterations }\end{array}$ & $\begin{array}{c}\text { Mean Gap } \\
\mathbf{( \% )}\end{array}$ & $\begin{array}{c}\text { Mean Gap * } \\
\text { from BKS (\%) }\end{array}$ & $\begin{array}{c}\text { CPU Time } \\
\text { (s) }\end{array}$ \\
\hline 10 & 45.74 & 56.13 & 11.35 & 0.27 \\
20 & 161.19 & 63.33 & 6.17 & 0.35 \\
30 & 289.55 & 64.29 & 5.59 & 0.42 \\
40 & 567.50 & 83.01 & 0.00 & 0.46 \\
50 & 418.71 & 69.16 & 3.81 & 0.49 \\
60 & 573.67 & 72.82 & 3.25 & 0.57 \\
70 & 674.40 & 76.29 & 2.74 & 0.67 \\
80 & 730.14 & 72.96 & 2.25 & 0.73 \\
90 & 832.54 & 73.76 & 2.15 & 0.80 \\
100 & 884.34 & 74.69 & 1.87 & 0.97 \\
\hline
\end{tabular}

Table 6. Results obtained by $G A_{H+P}$.

\begin{tabular}{ccccc}
\hline $\begin{array}{c}\text { Instance } \\
\text { Family }\end{array}$ & $\begin{array}{c}\text { Average Number } \\
\text { of Iterations }\end{array}$ & $\begin{array}{c}\text { Mean Gap } \\
\mathbf{( \% )}\end{array}$ & $\begin{array}{c}\text { Mean Gap * } \\
\text { from BKS (\%) }\end{array}$ & $\begin{array}{c}\text { CPU Time } \\
\text { (s) }\end{array}$ \\
\hline 10 & 115.50 & 66.33 & 3.93 & 0.32 \\
20 & 279.74 & 72.60 & 0.06 & 0.43 \\
30 & 422.37 & 72.65 & 0.00 & 0.53 \\
40 & 295.50 & 83.01 & 0.00 & 0.60 \\
50 & 609.03 & 75.06 & 0.03 & 0.63 \\
60 & 716.57 & 77.94 & 0.10 & 0.73 \\
70 & 781.95 & 80.60 & 0.18 & 0.83 \\
80 & 835.20 & 75.93 & 0.44 & 0.92 \\
90 & 892.58 & 76.28 & 0.64 & 1.01 \\
100 & 904.72 & 75.70 & 1.28 & 1.19 \\
\hline
\end{tabular}


Figure 3 illustrates the evolution of the gap over iterations of $G A_{H+p}$ on an instance with 100 components $\left(\right.$ gap $\left._{\text {gen }}=\frac{\text { best }_{\text {sol }_{\text {gen }}}-\text { best }_{\text {sol }_{5000}}}{\text { best }_{50 l_{500}}} \cdot 100\right)$. In the first iteration, the gap is $86.81 \%$, whereas at the $1000^{\text {th }}$ iteration the gap is reduced to $1.31 \%$. The gap finally reaches $0.00 \%$ at iteration 2132 . Ultimately, $98.48 \%$ of the improvement is achieved during the first 1000 iterations.

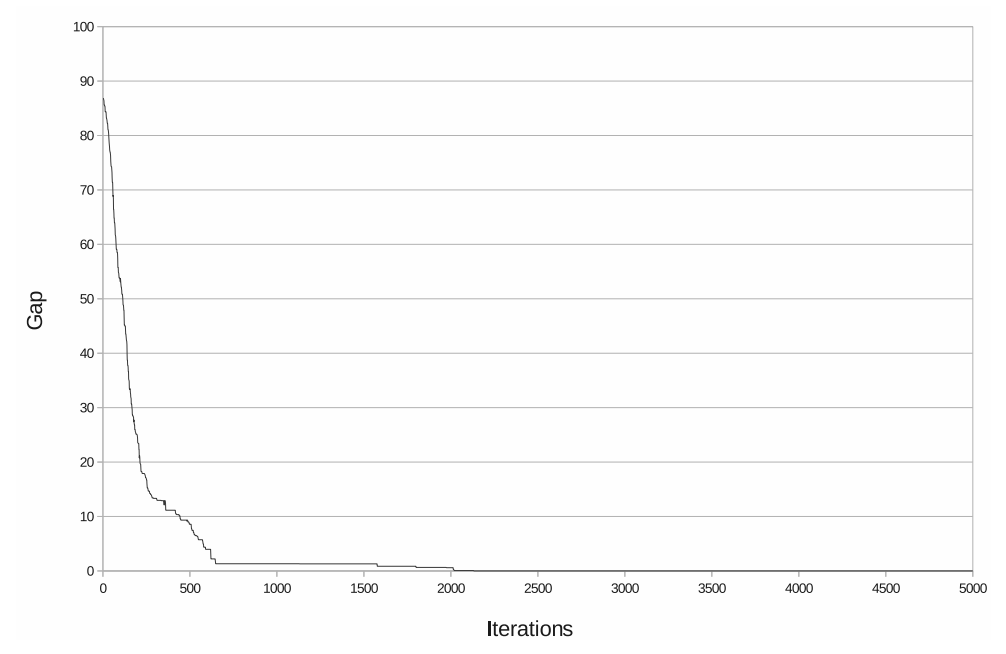

Figure 3. Evolution of the gap to the best known solution (BKS) over iterations.

Another set of tests had already been done, we adapted B\&B from [39] to policy 0 and applied it directly to the instances with a small number of suppliers (up to 50). For larger instances, the adapted $\mathrm{B} \& \mathrm{~B}$ was used as a beam search algorithm (only the most promising nodes are explored) to reduce the calculation time. Thus, the results were not exact but approximate. The tests show that the gap between the beam search and the optimal solution is less than $2.5 \%$. The quality of the beam algorithm is very good, as the beam search found optimal solutions for 491 of the 500 tests executed. Note that the optimal solutions found by $B \& B$ or beam search are also optimal for our problem for policy 0 and feasible for other policies, so they can be used as upper bounds in our study.

In order to verify the pertinence of our approach and assess the efficiency of the genetic algorithm, we compare the results of our $G A_{H+P}$ model with the upper and lower bounds (see Table 7). The table lists the names of the instance families (corresponding to the number of suppliers) along with the mean gaps from the lower and upper bounds. As each family has 100 instances, the mean gaps in percentage format are calculated as follows:

$$
\begin{aligned}
& \text { mean } \operatorname{GAP}\left(G A_{H+P}, \mathrm{LB}\right)=\left(\frac{\sum_{k=1}^{K} \frac{G A_{H+P}^{k}-L B^{k}}{L B^{k}}}{K}\right) \times 100 \\
& \text { mean } \operatorname{GAP}\left(G A_{H+P}, \mathrm{UB}\right)=\left(\frac{\sum_{k=1}^{K} \frac{U B^{k}-G A_{H+P}^{k}}{G A_{H+P}^{k}}}{K}\right) \times 100
\end{aligned}
$$

where $G A_{H+P}^{k}, L B^{k}$ and $U B^{k}$ are the result of GA, lower bound and upper bound to the problem on instance $k$, respectively and $K=100$ (instances by family). 
Table 7. Gaps between the results of $G A_{H+P}$ and upper and lower bounds.

\begin{tabular}{ccc}
\hline Instance Family & Mean GAP $\left(G A_{H+P}, \mathrm{LB}\right)(\%)$ & Mean GAP $\left(G A_{H+P}, \mathrm{UB}\right)(\%)$ \\
\hline 10 & 10.89 & 145.89 \\
20 & 6.33 & 181.06 \\
30 & 6.00 & 183.49 \\
40 & 8.16 & 185.18 \\
50 & 8.77 & 194.95 \\
60 & 10.24 & 194.31 \\
70 & 12.00 & 192.26 \\
80 & 14.34 & 192.57 \\
90 & 10.97 & 191.04 \\
100 & 10.35 & 190.74 \\
\hline
\end{tabular}

The mean gap between the lower bound and the $G A_{H+P}$ is less than $15 \%$, and smaller gaps are observed for instances with 20 to 50 suppliers.

Note: the mean gap between the upper bound and the $G A_{H+P}$ is very large, ranging between $145.89 \%$ and $194.95 \%$. Thus, the solutions without the pricing policies give very poor upper bounds. This shows the huge impact of the applied pricing policies for lead-time uncertainty reduction on the total cost reduction. Even if there is an additional purchasing cost, the cost saving with reduction of the lead-time uncertainty is much bigger and so the total cost is drastically reduced.

\section{Managerial Insights}

The proposed model has challenging new settings. In particular we add the purchasing cost depending on supplier reliability. This could be a useful aid for decision makers because it opens the possibility of solving very important problems not currently solved, in particular, to decide to outsource or not, if yes, to which suppliers and countries, but also to negotiate purchase prices versus lead time decisions.

The results depend on the behavior of the decision maker and his choices when he/she is faced with uncertainty and risks. If the decision maker is a risk-taking manager (risk $k_{\max }$ ), he/she will be reluctant to pay more to reduce the uncertainty, and hence will always choose $A P C^{0}$, which is a policy with zero additional purchase cost but with maximum uncertainty. In this case, we have the model proposed in [39] that we used to calculate upper bounds. On the other hand, if the decision maker is risk-averse, he/she will be willing to pay the maximum $A P C^{u_{0}-1}\left(r_{i s k_{m i n}}\right)$. In this case, the uncertainty disappears and the problem becomes deterministic. In the deterministic case, ordering just-in-time implies zero inventory holding and backlogging costs, leaving the only cost as $\sum_{i} A P C_{i}^{u_{0}-1}$.

Table 8 compares our lead-time uncertainty-reducing pricing and inventory control model with these two strategies on three groups of scenarios. In the first group (G1), we considered a low average APC increase $\left(0<\overline{\triangle A P C} \leq \frac{H}{5 n}\right)$. In the second group (G2), we considered the case of an average APC increase between $\frac{2}{3} \frac{H}{n}$ and $\frac{H}{n}$. Finally, in the third group (G3), we considered the case of an average APC increase greater than holding and backlogging costs $\left(2 \frac{H}{n} \leq \overline{\triangle A P C} \leq 5 \frac{H}{n}\right)$.

Table 8. Decisionmaker behavior analysis.

\begin{tabular}{cccc}
\hline Instance Group & $\begin{array}{c}\text { Mean GAP } \\
\left(G A_{\left.\boldsymbol{H}+\boldsymbol{P}, \boldsymbol{r i s} \boldsymbol{k}_{\text {min }}\right)(\%)}\right.\end{array}$ & $\begin{array}{c}\text { Mean GAP } \\
\left(G A_{\boldsymbol{H}+\boldsymbol{P},} \boldsymbol{r i s k}_{\text {max }}\right)(\%)\end{array}$ & $\begin{array}{c}\text { Mean GAP } \\
\left(\text { risk }_{\text {min }}, \boldsymbol{r i s k}_{\text {max }}\right)(\%)\end{array}$ \\
\hline G1 & 0.57 & 7014.81 & 6993.03 \\
G2 & 108.20 & 4.04 & -49.68 \\
G3 & 492.31 & $1.78 \cdot 10^{-5}$ & -83.17 \\
\hline
\end{tabular}


Mean GAPs were computed as follows:

$$
\begin{aligned}
\text { mean } \operatorname{GAP}\left(G A_{H+P}, r i s k_{\text {min }}\right) & =\left(\frac{\sum_{k=1}^{K} \frac{r i s k_{\text {min }}^{k}-G A_{H+P}^{k}}{G A_{H+P}^{k}}}{K}\right) \times 100 \\
\text { mean } \operatorname{GAP}\left(G A_{H+P}, r i s k_{\text {max }}\right) & =\left(\frac{\sum_{k=1}^{K} \frac{r i s k_{\text {max }}^{k}-G A_{H+P}^{k}}{G A_{H+P}^{k}}}{K}\right) \times 100 \\
\text { mean } \operatorname{GAP}\left(\text { risk }_{\text {max }}, \text { ris }_{\text {min }}\right) & =\left(\frac{\sum_{k=1}^{K} \frac{r i s k_{\text {max }}^{k}-r i s k_{\text {min }}^{k}}{r i s k_{\text {min }}^{k}}}{K}\right) \times 100
\end{aligned}
$$

Comparison of two simple strategies found that when the average APC increase is small, a risk-avoiding strategy is almost $7000 \%$ better on average than a risk-taking strategy. Similarly, if the average APC increase is very big, a risk-taking strategy is $83.17 \%$ better on average than a risk-avoiding strategy. Obviously, there is no reason to take risks when it is cheaper to pay to reduce the uncertainty. Nevertheless, when the cost of reducing the uncertainty exceeds the inventory holding and backlogging costs caused by the uncertainty, then the decision maker should be open to taking risks.

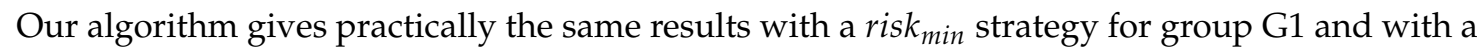
risk $k_{\max }$ strategy for group G3. The most interesting case is when the average APC increase is close to the inventory holding and backlogging costs, where $G A_{H+P}$ gave the best total cost and the gap to the risk $k_{\min }$ strategy was $108.2 \%$ whereas the gap to the risk $k_{\max }$ strategy was $4.04 \%$. In other words, our $G A_{H+P}$ adapts itself to changes in inventory holding, backlogging and additional purchase costs and chooses the best-suited strategy with regard to risks.

\section{Discussion}

A key problem with much literature on replenishment policy for assembly systems under uncertainty of lead times is that research has tended to focus on reducing the costs related to uncertainty rather than establishing a suppliers selection strategy in order to negotiate purchase prices and uncertainty costs. All previous research concentrates on ordering policies by optimizing order quantities [3,34-36,39-42], order release dates and planned lead times [14-18,22,23].

This study is the first investigation that aimed at highlighting the usefulness of considering supplier selection/replacement strategies to negotiate purchase prices and delivery delays for OLAS and multi-period replenishment planning. It provides the basis for a new way to consider not only the probability distributions of lead-times of suppliers but also their prices, Thus, the present findings might help to optimize not only replenishment policy, but also purchasing policy. For a given unit, it is now possible to model several alternative suppliers with alternative pricing and lead-time uncertainties, and evaluate their impacts on the total cost. The proposed model has the potential to be applied to ATO environments $[19,20,22]$ and to CTO environments [23], for example, if components and semi-finished products are bought abroad and shipped from various locations. The proposed approach could possibly enable decision makers to select suppliers and plan the order release dates based on planned lead times and purchasing policies predefined by suppliers.

In our view, these results constitute an excellent initial step toward including the selection of suppliers in replenishment policy. Please note that with Industry 4.0 technologies the selection of suppliers and negotiation of conditions will move from the strategic and offline approach to real time online negotiations. Thus, the importance of such models will increase. 
Despite our research showing the importance of optimizing purchasing policies, we are aware that it may have several limitations. The first is that the model is only valid when the demand is known and constant. This hypothesis is considered because, at the moment, it is difficult to express the dependence between periods and levels when the demand is completely dynamic. Research into solving this problem is already in progress. Second, the mathematical formulation needs to be extended in order to study complex structures such as BOMs with several levels. Our future work will concentrate on this limitation. Techniques, that are developed in $[22,57,58]$ in order to model multi-level structures and in [59] in the field of project planning, will be investigated. Third, the current study has only examined the uncertainty of lead times. Consequently, we neglected other types of uncertainty such as demand and quality. Further work needs to be carried out to investigate more than one source of uncertainty. The development of more complex models with several stochastic parameters to study more complex structures will be an on-going challenge for future years.

\section{Conclusions}

This paper deals with a pricing and replenishment problem for one-level assembly systems under component lead-time uncertainty. We focused on finding optimal values for the planned lead times (or order release dates) and purchasing prices. A linear model was developed, and a decomposition approach was proposed to calculate a lower bound, while upper bounds were calculated using a B\&B and beam search algorithms developed for a particular case with fixed purchasing prices.

For the general case, we also proposed a genetic algorithm. Solution quality was improved by a heuristic to create initial solutions and a perturbation technique to diversify the search. The genetic algorithm was evaluated. Its results were compared against lower and upper bounds. Test results showed that having several policies with a higher purchasing price but lower uncertainty drastically improves the total cost. Comparisons with risk-taking and risk-avoiding behaviors showed that the proposed genetic algorithm adapts itself to the parameters of the supply chain and gives valuable insights to the decision makers.

The problem is a problem of negotiation of planned lead times and purchasing costs and, in a more general perspective, a problem of analyzing outsourcing strategies and supplier selection. As noted in the results and discussion, the proposed model could help the decision maker faced with a set of suppliers characterized by their prices and the probability distributions of their lead-times. Taking into account these parameters gives the possibility of optimizing not only replenishment policy, but also purchasing prices. Therefore, the decision maker could find a good compromise between the cost of uncertainty and the cost of purchasing. In this way, he/she will be able to know if it is preferable to (i) pay more to reduce uncertainty, or (ii) pay less to reduce purchasing costs. This question remains open. Many companies are faced with this dilemma: sourcing from abroad with low prices and uncertain lead times versus sourcing from local suppliers with higher prices and almost deterministic lead times.

Author Contributions: Conceptualization, A.D. and F.H.; methodology, H.M.A., O.B.-A. and F.H.; software, H.M.A. and F.H.; validation, O.B.-A., A.D., F.H. and H.M.A.; formal analysis, H.M.A. and F.H.; investigation, O.B.-A., H.M.A., F.H. and A.D.; resources, F.H., O.B.-A. and H.M.A.; data curation, H.M.A. and F.H.; writingoriginal draft preparation, H.M.A., O.B.-A. and F.H.; visualization, O.B.-A. and F.H.; supervision, A.D. and F.H.; project administration, A.D. and F.H. All authors have read and agreed to the published version of the manuscript.

Funding: This research received no external funding.

Conflicts of Interest: The authors declare no conflict of interest.

\section{Abbreviations}

This manuscript uses the following abbreviations:

APC Additional Purchase Cost

ATO Assemble-To-Order

BKS Best Known Solution 


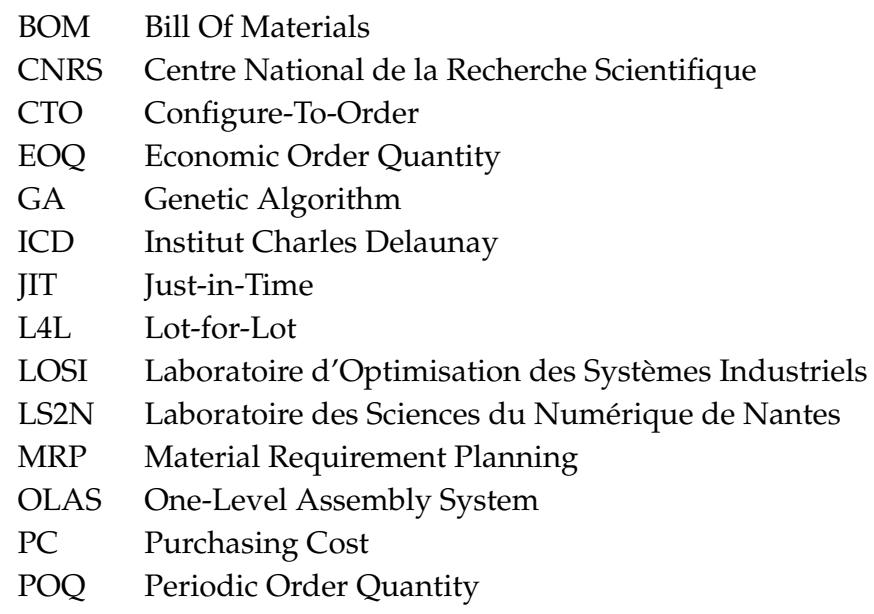

\section{References}

1. Simić, D.; Svirčević, V.; Simić, S. A hybrid evolutionary model for supplier assessment and selection in inbound logistics. J. Appl. Logic. 2015, 13, 138-147. [CrossRef]

2. Burke, G.J.; Carrillo, J.E.; Vakharia, A.J. Sourcing decisions with stochastic supplier reliability and stochastic demand. Prod. Oper. Manag. 2009, 18, 475-484. [CrossRef]

3. Louly, M.A.; Dolgui, A.; Hnaien, F. Optimal supply planning in MRP environments for assembly systems with random component procurement times. Int. J. Prod. Res. 2008, 46, 5441-5467. [CrossRef]

4. Weeks, J.K. A simulation study of predictable due-date. Manag. Sci. 1979, 25, 363-373. [CrossRef]

5. Yano, C.A. Setting planned leadtimes in serial production systems with tardiness costs. Manag. Sci. 1987, 33, 95-106. [CrossRef]

6. Gong, L.; de Kok, T.; Ding, J. Optimal leadtimes planning in a serial production system. Manag. Sci. 1994, 40, 629-632. [CrossRef]

7. Elhafsi, M. Optimal leadtimes planning in serial production systems with earliness and tardiness costs. IIE Trans. 2002, 34, 233-243. [CrossRef]

8. Yano, C. Stochastic leadtimes in two-level assembly systems. IIE Trans. 1987, 19, 95-106. [CrossRef]

9. Kumar, A. Component inventory cost in an assembly problem with uncertain supplier Lead-Times. IIE Trans. 1987, 21, 112-121. [CrossRef]

10. Chu, C.; Proth, J.M.; Xie, X. Supply management in assembly systems. Nav. Res. Log. 1993, 40, $933-949$. [CrossRef]

11. Hegedus, M.G.; Hopp, W.J. Due date setting with supply constraints in systems using MRP. Comput. Ind. Eng. 2001, 39, 293-305. [CrossRef]

12. Hegedus, M.G.; Hopp, W.J. Setting procurement safety lead-times for assembly systems. Int. J. Prod. Res. 2001, 39, 3459-3478. [CrossRef]

13. Gurnani, H.; Akella, R.; Lehoczky, J. Optimal order policies in assembly systems with random demand and random supplier delivery. IIE Trans. 1996, 28, 865-878. [CrossRef]

14. Hnaien, F.; Delorme, X.; Dolgui, A. Genetic algorithm for supply planning in two-level assembly systems with random lead times. Eng. Appl. Artif. Intel. 2009, 22, 906-915. [CrossRef]

15. Hnaien, F.; Delorme, X.; Dolgui, A. Multi-objective optimization for inventory control in two-level assembly systems under uncertainty of lead times. Comput. Oper. Res. 2010, 37, 1835-1843. [CrossRef]

16. Fallah-Jamshidi, S.; Karimi, N.; Zandieh, M. A hybrid multi-objective genetic algorithm for planning order release date in two-level assembly system with random lead times. Expert Syst. Appl. 2011, 38, 13549-13554. [CrossRef]

17. Sakiani, R.; Ghomi, S.F.; Zandieh, M. Multi-objective supply planning for two-level assembly systems with stochastic lead times. Comput Oper. Res. 2012, 39, 1325-1332. [CrossRef]

18. Ben-Ammar, O.; Dolgui, A. Optimal order release dates for two-level assembly systems with stochastic lead times at each level. Int. J. Prod. Res. 2018, 56, 4226-4242. [CrossRef]

19. Guiras, Z.; Turki, S.; Rezg, N.; Dolgui, A. Optimization of two-level disassembly/remanufacturing/assembly system with an integrated maintenance strategy. Appl. Sci. 2018, 8, 666. [CrossRef] 
20. Guiras, Z.; Turki, S.; Rezg, N.; Dolgui, A. Optimal maintenance plan for two-level assembly system and risk study of machine failure. Int. J. Prod. Res. 2019, 57, 2446-2463. [CrossRef]

21. Axsäter, S. Planning order releases for an assembly system with random operation times. OR Spectrum 2005, 27, 459-470. [CrossRef]

22. Ben-Ammar, O.; Dolgui, A.; Wu, D.D. Planned lead times optimization for multi-level assembly systems under uncertainties. Omega 2018, 78, 39-56. [CrossRef]

23. Jansen, S.; Atan, Z.; Adan, I.; de Kok, T. Setting optimal planned leadtimes in configure-to-order assembly systems. Eur. J. Oper. Res. 2019, 273, 585-595. [CrossRef]

24. Foote, B.; Kebriaei, N.; Kumin, H. Heuristic policies for inventory ordering problems with long and randomly varying lead times. J. Oper. Manage. 1988, 7, 115-124. [CrossRef]

25. Ehrhardt, R. (s, S) policies for a dynamic inventory model with stochastic lead times. Oper. Res. 1984, 32, 121-132. [CrossRef]

26. Magson, D. Stock control when the lead time cannot be considered constant. J. Oper. Res. Soc. 1979, 30, 317-322. [CrossRef]

27. Das, C. Effect of lead time on inventory: a static analysis. J. Oper. Res. Soc. 1975, 26, 273-282. [CrossRef]

28. Disney, S.M.; Maltz, A.; Wang, X.; Warburton, R.D. Inventory management for stochastic lead times with order crossovers. Eur. J. Oper. Res. 2016, 248, 473-486. [CrossRef]

29. Srinivasan, M.; Novack, R.; Thomas, D. Optimal and approximate policies for inventory systems with order crossover. J. Bus. Logist. 2011, 32, 180-193. [CrossRef]

30. Muharremoglu, A.; Yang, N. Inventory management with an exogenous supply process. Oper. Res. 2010, 58, 111-129. [CrossRef]

31. Robinson, L.W.; Bradley, J.R.; Thomas, L.J. Consequences of order crossover under order-up-to inventory policies. Manuf. Serv. Op. 2001, 3, 175-188. [CrossRef]

32. Graves, S. Logistics of Production and Inventory. In Handbooks in Operations Research and Management Science; Elsevier: Amsterdam, The Netherlands, 1993; Volume 4.

33. Dolgui, A.; Ben-Ammar, O.; Hnaien, F.; Ould-Louly, M.A. A state of the art on supply planning and inventory control under lead time uncertainty. Stud. Inform. Control 2013, 22, 255-268. [CrossRef]

34. Liberatore, M. The EOQ model under stochastic lead times. Oper. Res. 1979, 27, 391-396. [CrossRef]

35. Fujiwara, O.; Sedarage, D. An optimal (Q,r) policy for a multipart assembly system under stochastic part procurement lead times. Eur. J. Oper. Res. 1997, 100, 550-556. [CrossRef]

36. Ould-Louly, M.A.; Dolgui, A. Optimal time phasing and periodicity for MRP with POQ policy. Int. J. Prod. Econ. 2011, 131, 76-86. [CrossRef]

37. Dolgui, A.; Ould-Louly, M.A. A model for supply planning under lead time uncertainty. Int. J. Prod. Econ. 2002, 78, 145-152. [CrossRef]

38. Ould-Louly, M.A.; Dolgui, A. The MPS Parametrization under Lead Time Uncertainty. Int. J. Prod. Econ. 2004, 90, 369-376. [CrossRef]

39. Ould-Louly, M.A.; Dolgui, A. Calculating safety stocks for assembly systems with random component procurement lead times: A branch and bound algorithm. Eur. J. Oper. Res. 2009, 199, 723-731. [CrossRef]

40. Ould-Louly, M.A.; Dolgui, A. A note on analytic calculation of planned lead times for assembly systems under POQ policy and service level constraint. Int. J. Prod. Econ. 2010, 140, 778 - 781. [CrossRef]

41. Ould-Louly, M.A.; Dolgui, A. Optimal MRP parameters for a single item inventory with random replenishment lead time, POQ policy and service level constraint. Int. J. Prod. Econ. 2013, 143, 35-40. [CrossRef]

42. Shojaie, S.H.; Bahoosh, A.; Pourhassan, M. A study on MRP with using leads time, order quality and service level over a single inventory. J. UMP Soc. Sci. Technol. Manag. 2015, 3, 235-239.

43. Molinder, A. Joint optimization of lot-sizes, safety stocks and safety lead times in an MRP system. Int. J. Prod. Res. 1997, 35, 983-994. [CrossRef]

44. Bollapragada, R.; Kuppusamy, S.; Rao, U. Component procurement and end product assembly in an uncertain supply and demand environment. Int. J. Prod. Res. 2014, 53, 969-982. [CrossRef]

45. Yao, M.; Minner, S. Review of multi-supplier inventory models in supply chain management: An update. SSRN Electron. J. 2017. [CrossRef]

46. Yano, C.A.; Gilbert, S.M. Coordinated pricing and production/procurement decisions: A review. In Managing Business Interfaces; Springer: Berlin/Heidelberg, Germany, 2005; pp. 65-103. 
47. Chan, L.M.; Shen, Z.M.; Simchi-Levi, D.; Swann, J.L. Coordination of pricing and inventory decisions: A survey and classification. In Handbook of Quantitative Supply Chain Analysis; Springer: Berlin/Heidelberg, Germany, 2004; pp. 335-392.

48. Elmaghraby, W.; Keskinocak, P. Dynamic pricing in the presence of inventory considerations: Research overview, current practices, and future directions. Manag. Sci. 2003, 49, 1287-1309. [CrossRef]

49. Golmohammadi, A.; Hassini, E. Review of supplier diversification and pricing strategies under random supply and demand. Int. J. Prod. Res. 2020, 1-33. [CrossRef]

50. Anupindi, R.; Akella, R. Diversification under supply uncertainty. Manag. Sci. 1993, 39, 944-963. [CrossRef]

51. Gurnani, H.; Akella, R.; Lehoczky, J. Supply management in assembly systems with random yield and random demand. IIE Trans. 2000, 32, 701-714. [CrossRef]

52. Pan, W.; So, K.C. Optimal product pricing and component production quantities for an assembly system under supply uncertainty. Oper. Res. 2010, 58, 1792-1797. [CrossRef]

53. Ould-Louly, M.A.; Dolgui, A. Generalized newsboy model to compute the optimal planned lead times in assembly systems. Int. J. Prod. Res. 2002, 40, 4401-4414. [CrossRef]

54. Hnaien, F.; Afsar, H.M.; Dolgui, A. Integration of additional purchase cost to reduce the lead time uncertainty for one level assembly system. In Proceedings of the 7th IFAC Conference on Manufacturing Modelling, Management, and Control; Bakhtadze, N., Dolgui, A.V.L., Eds.; Elsevier: St. Petersburg, Russia, 2013; Volume 7, pp. 383-388.

55. Golberg, D. Genetic Algorithms in Search, Optimisation and Machine Learning; Addison Wesley: Reading, MA, USA, 1989.

56. Holland, J. Adaptation in Natural and Artificial Systems; University of Michigan Press: Ann Arbor, MI, USA, 1975.

57. Atan, Z.; de Kok, T.; Dellaert, N.P.; van Boxel, R.; Janssen, F. Setting planned leadtimes in customer-order-driven assembly systems. Manuf. Serv. Oper. Manag. 2016, 18, 122-140. [CrossRef]

58. Jansen, S.; Atan, Z.; Adan, I.J.; de Kok, A. Newsvendor equations for production networks. Oper. Res. Lett. 2018, 46, 599-604. [CrossRef]

59. Trietsch, D. Optimal feeding buffers for projects or batch supply chains by an exact generalization of the newsvendor result. Int. J. Prod. Res. 2006, 44, 627-637. [CrossRef]

(C) 2020 by the authors. Licensee MDPI, Basel, Switzerland. This article is an open access article distributed under the terms and conditions of the Creative Commons Attribution (CC BY) license (http://creativecommons.org/licenses/by/4.0/). 